\title{
RANCANG BANGUN MODUL PROTEKSI ARUS BEBAN LEBIH DAN HUBUNG SINGKAT
}

\author{
Aceng Daud \\ Jurusan Teknik Konversi Energi \\ Email:daud.polban@gmail.com
}

\begin{abstract}
ABSTRAK
Motor listrik adalah salah pealatan listrik yang banyak digunakan di dunia yang peranannya sangat penting untuk menggerakan mesin-mesin di indutsri.. Maka dari itu motor ini membutuhkan sebuah Rele Proteksi yang berfungsi sebagai pemutus daya listrik dari jaringan ketika beban berlebihan atau ketika terjadi hubung singkat pada belitan statornya. Dalam penelitian ini dibuat rele proteksi motor berbasis mikrokontroller arduino uno dengan beberapa komponen pendukung yang di antaranya berupa sensor arus menggunakan ACS 712 yang mengkonversi arus menjadi tegangan 0-5 V. Tegangan output dari sensor arus diprogram menggunakan software arduino uno untuk menggerakan sebuah rele yang akan memutuskan kontaktor dan menyalakan indikator ketika terjadi arus berlebih. Dari hasil pengujian, proteksi dapat bekerja ketika arus pada generator melebihi arus setting yang telah ditentukan dengan waktu tunda rele selama $200 \mathrm{~ms}$.
\end{abstract}

Kata Kunci : Motor Lsitrik, Rele Proteksi, Kontaktor, Arduino UNO, Mikrokontroller, sensor arus, ACS 712

\begin{abstract}
Electric motors are one of the electric tools that are widely used in the world whose role is very important to drive the machines of the industry. Therefore this motor needs a protection relay that functions as a breaker of electrical power from the network when overloaded or when a short circuit occurs either at the stator winding. In this research, an arduino uno microcontroller-based motor protection relay relays with several supporting components including a current sensor using ACS 712 which converts current to 0-5V voltage. The output voltage of the current sensor is programmed using the arduino uno software to drive a relay that will disconnecting the contactor and turning on the indicator when there is excessive current. From the test results, protection can work when the current on the generator exceeds the predetermined current setting with a relay delay time of 100 ms.
\end{abstract}

Keywords: Electric Motor, Protection Relay, Contactor, Arduino UNO, Microcontroller, current sensor, ACS 712

\section{PENDAHULUAN}

Motor listrik adalah salah satu peralatan penting di dunia yang berfungsi untuk menggerakan mesin-mesin di industri. Pemakaian motor yang mengharuskan bekerja secara terus menerus akan membutuhkan sebuah proteksi yang berfungsi sebagai pengaman ketika terjadi gangguan pada motor tersebut. Rele dan kontaktor adalah salah satu peralatan lsitrik yang dapat digunakan dalam proteksi motor listrik. Rele ini akan berfungsi ketika mendapat masukan atau sinyal dari sensor arus apabila terjadi arus yang tidak sesuai dengan set point yang telah ditentukan sebelumnya sehingga rele ini akan bekerja dan kontaktor akan memutus aliran listrik dari saluran yang mensuplai motor.

Mikrokontroller digunakan sebagai aplikasi agar sistem rele proteksi yang 
digunakan akan menampilkan sinyal secara digital. Program rele proteksi ini yaitu dengan menggunakan mikrokontroller arduino UNO sebagai basis kontrollernya dan sensor terhadap arus yang akan diproteksi ini meggunakan ACS712 ELCTR 20A-T, sensor ini dapat digunakan untuk mendeteksi atau membaca arus hingga \pm 20 A AC maupun DC.

Karakteristik proteksi rele arus lebih ada tiga macam yaitu rele arus lebih seketika (moment-instaneous) yaitu jenis rele yang jangka waktu kerja rele dimulai saat mengalami pick-up sampai selesai kerja rele yakni sekitar $20 \approx 100$ detik tanpa adanya penundaan waktu. Yang kedua yaitu rele arus lebih waktu tertentu (definite time) yaitu jenis rele arus lebih dimana jangka waktu rele mulai pick-up sampai selesainya kerja rele dapat diperpanjang dengan nilai tertentu dan tidak tergantung dari besarnya arus yang mengerjakannya (tergantung dari besarnya arus setting, melebihi arus setting maka waktu kerja rele ditentukan oleh waktu settingnya). Dan yang ketiga yaitu rele arus lebih berbanding terbalik yaitu jenis rele arus lebih dimana jangka waktu rele mulai pick-up sampai selesainya kerja rele tergantung dari besarnya arus yang melewati kumparan rele-nya, dengan kata lain rele tersebut mempunyai sifat terbalik untuk nilai arus dan waktu bekerjanya.

\section{TINJAUAN PUSTAKA}

\subsection{Jenis Jenis Gangguan Pada Motor}

Secara umum, gangguan pada motor induksi terjadi pada bearing, belitan stator, bar rotor, dan poros. Selain karena ketidakseragaman celah udara antara permukaan stator-dalam dan permukaan rotor-luar, gangguan juga terjadi. Berbagai studi telah dilakukan sejauh ini untuk mempelajari keandalan motor, kinerja mereka, dan gangguan terjadi. Studi statistik IEEE dan EPRI (Electric Power Research Institute) untuk gangguan motorik dikutip dalam referensi. Bagian dari penelitian ini adalah untuk menentukan persentase gangguan yang berbeda sehubungan dengan jumlah total gangguan. Studi tentang IEEE dilakukan pada berbagai motor dalam aplikasi industri. Sesuai Standar IEEE 4931997, Gangguan paling umum dan kemunculan statistiknya ditunjukkan pada Tabel 2.2. Di bawah sponsor EPRI, sebuah penelitian dilakukan oleh General Electric Company berdasarkan laporan dari produsen motor. Sesuai laporan mereka, Gangguan motor utama disajikan pada Tabel 2.1.

Tabel 2.1 Kemungkinan terjadinya Gangguan pada motor induksi $[7,9]$

\begin{tabular}{|l|l|l|l|l|}
\hline Dikaji oleh & $\begin{array}{l}\text { Gangguan } \\
\text { bantalan (\%) }\end{array}$ & $\begin{array}{l}\text { Gangguan } \\
\text { stator (\%) }\end{array}$ & $\begin{array}{l}\text { Gangguan } \\
\text { rotor (\%) }\end{array}$ & Lainnya (\%) \\
\hline IEEE & 42 & 28 & 8 & 22 \\
\hline EPR & 41 & 36 & 9 & 14 \\
\hline
\end{tabular}

\subsection{Proteksi Motor}

Perlindungan motor listrik harus sederhana dan dapat diandalkan, karena penggunaan perlindungan yang kompleks mahal untuk biaya modal dan tidak dibenarkan. Untuk motor dengan kekuatan lebih dari 2 MVA, perlindungan yang lebih kompleks dapat digunakan, karena mesin ini biasanya mahal, atau mereka digunakan di tempat-tempat penting untuk kebutuhan pembangkit listrik dan mekanisme perusahaan industri.

Untuk melindungi dari hubung singkat fase-ke-fase, pemutus arus dan perlindungan diferensial. Pemutus arus direkomendasikan untuk perlindungan motor listrik dengan daya hingga $5000 \mathrm{~kW}$ jika memiliki sensitivitas yang diperlukan untuk kerusakan di terminal. Jika sensitivitas pemutus arus tidak mencukupi, perlindungan diferensial harus digunakan. Penggunaan perlindungan diferensial disarankan mulai dari daya (3500 - 4000) $\mathrm{kW}$.

\subsubsection{Pemutusan arus.}

Pemutus arus untuk motor hingga $2000 \mathrm{~kW}$, tidak termasuk motor listrik dari kebutuhan pembangkit sendiri, dilakukan oleh skema sirkuit tunggal (gambar 2.1-a) 


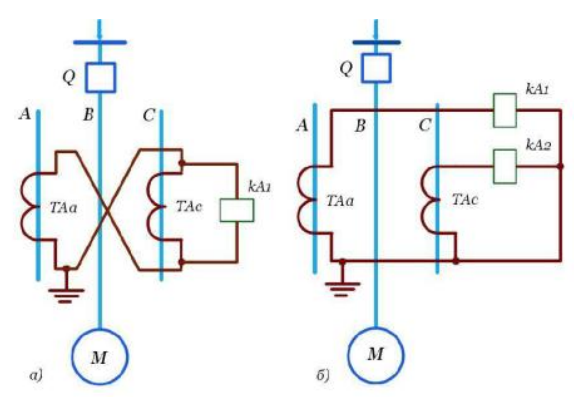

Gambar 21 Skema pemutus arus: a) rele tunggal, b) rele ganda

Pada motor listrik dengan daya (2000$4000 \mathrm{~kW})$, cutoff arus dilakukan menggunakan sirkuit dua-rele (gambar 2.1b). Jika faktor sensitivitas sirkuit satu sirkuit kurang dari dua, maka skema dua sirkuit harus digunakan pada mesin hingga 2000 $\mathrm{kW}$.

\subsubsection{Perlindungan diferensial.}

Pada motor dengan daya $4000 \mathrm{~kW}$ atau lebih, perlindungan diferensial longitudinal dipasang tanpa pengereman atau dengan pengereman. Untuk melakukan perlindungan dengan pengereman, pengereman dilakukan dari transformator arus yang dipasang di sisi terminal nol belitan stator. Arus operasi perlindungan dipilih dari kondisi kegagalan yang andal dalam start-up, self-starting, korsleting eksternal atau switching motor sinkron tidak sinkron.

\subsubsection{Rele termal.}

Rele termal - jenis perlindungan motor yang paling umum. Prinsip operasinya didasarkan pada kemungkinan arus listrik untuk memanaskan konduktor yang melaluinya mengalir. Bagian utama dari rele termal adalah pelat bimetalik. Yang, ketika dipanaskan, melengkung dan dengan demikian memutus kontak. Pelat pemanas terjadi ketika arus melebihi nilai yang diizinkan. Rele termal adalah perangkat listrik yang dirancang untuk melindungi motor listrik dari kelebihan arus. Jenis rele termal yang paling umum adalah TRP, TRN, RTL dan RTT.

\subsubsection{Sekring.}

Sekering adalah perangkat perlindungan yang paling sederhana dan paling umum. Tujuan dari sekering adalah untuk melepaskan konsumen (bagian dari sistem pencahayaan, mesin, dll.) Dari listrik dengan kelebihan arus atau korsleting yang terlalu tinggi. Pada saat yang sama, sejumlah besar panas melelehkan insert sekering yang melebur dan dengan demikian memutus sirkuit listrik. Menjadi alat pelindung paling umum, sekering pada saat yang sama sangat tidak sempurna. Sekering memiliki kapasitas pembatas pembatas yang relatif kecil. Untuk melindungi instalasi listrik bertegangan rendah, sekering seri PRS dan PN.

\subsection{Karakteristik Proteksi}

Ada tiga macam jenis proteksi rele arus lebih, yaitu :

1. Rele arus lebih seketika ( moment instaneous)

2. Rele arus lebih waktu tertentu (definite time)

3. Rele arus lebih berbandung terbalik ( inverse), dibagi menjadi:

- Rele berbanding terbalik biasa

- Rele sangat berbanding terbalik

- Rele sangat berbanding sekali

\subsubsection{Rele Arus Lebih Seketika}

Rele arus lebih seketika adalah jenis rele yang paling sederhana dimana jangka waktu kerja rele yaitu mulai saat mengalami pick-up sampai selesainya kerja rele sangat singkat yakni sekitar 20 - 100 milisecond tanpa adanya penundaan waktu. Berikut adalah gambar dari rangkaian rele arus lebih seketika.

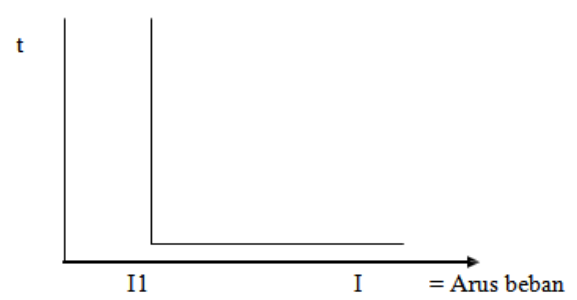

Gambar 2-2 Karakteristik Rele Arus Lebih Seketika 


\subsubsection{Rele Arus Lebih Waktu Tertentu}

Rele arus lebih tertentu adalah jenis rele arus lebih dimana jangka waktu rele mulai pick-up sampai selesainya kerja rele dapat diperpanjang dengan nilai tertentu dan tidak tergantung dari besarnya arus yang mengerjakannya (tergantung dari besarnya arus setting, melebihi arus setting maka waktu kerja rele ditentukan oleh waktu settingnya).

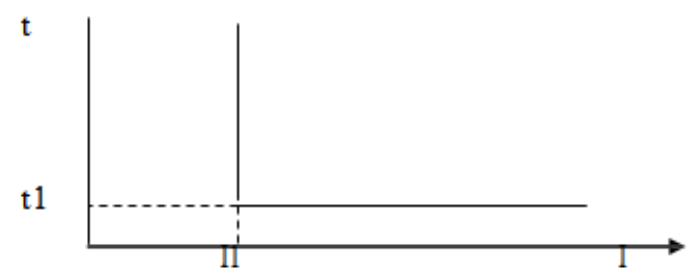

Gambar 2-3 Karakteristik Rele Arus Lebih Tertentu

Dengan memasang rele keterlambatan waktu $\mathrm{T}$ (Time lag rele), beroperasinya rangkaian rele akan tergantung pada penyetelan/setting waktu pada rele kelambatan waktunya. Sedangkan karakteristik kerjanya dapat dilihat pada gambar 2.3.

\subsubsection{Rele Arus Lebih Berbanding Lurus Terbalik}

Rele arus lebih dengan karakteristik waktu-arus berbanding terbalik adalah jenis rele arus lebih dimana jangka waktu rele mulai pick-up sampai selesainya kerja rele tergantung dari besarnya arus yang melewati kumparan rele-nya, dengan kata lain rele perancangan alat yang akan dibuat dengan menentukan rangkaian yang akan digunakan untuk dapat memproteksi dari suatu generator sinkron serta perhitungan setiap komponen yang akan digunakan agar bahan sesuai dengan desain dan setelah itu tahap pencarian bahan atau komponen komponen di pasaran.

Tahap berikutnya adalah proses perakitan alat yaitu dengan melakukan pembuatan rangkaian proteksi arus generator sinkron tiga fasa. Setelah selesai dilakukan perakitan, kemudian dilakukan tersebut mempunyai sifat terbalik untuk nilai arus dan waktu bekerjanya.

Bentuk sifat keterbalikan antara arus dan waktu kerja rele ini bermacam macam, akan tetapi kesemuanyaaitu dapat digolongkan menjadi 3 golongan sebagai berikut:

- Berbanding terbalik biasa (inverse)

- Sangat berbanding terbalik (very inverse)

- Sangat berbanding terbalik sekali (extremely inverse)

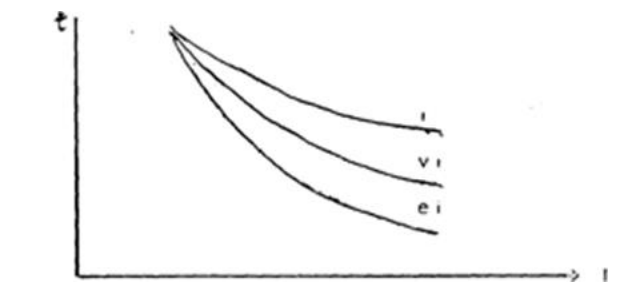

\section{Gambar 2-4 Karakteristik Rele Arus Lebih Berbanding Terbalik}

\section{METODELOGI PENELITIAN}

\subsection{Metodologi Penyelesaian}

Pada proses penyelesaian tugas akhir ini terdapat beberapa prosedur yaitu mulai dari studi literatur, bimbingan, perancangan serta pembuatan alat dan program, pengujian dan pembuatan laporan. Proses yang dilakukan untuk menyelesaikan penelitian ini adalah dengan melakukan studi literatur yang berkenaan dengan topik atau yang sesuai dengan materi penelitian ini baik itu dari buku, jurnal, maupun internet. Proses selanjutnya yaitu

simulasi dengan software. Hal ini bertujuan untuk memastikan agar rangkaian dari proteksi ini sudah sesuai. Adapun diagram alir dalam proses perancangan rangkaian arus generartor sinkron ditunjukan pada Gambar 3.1. 


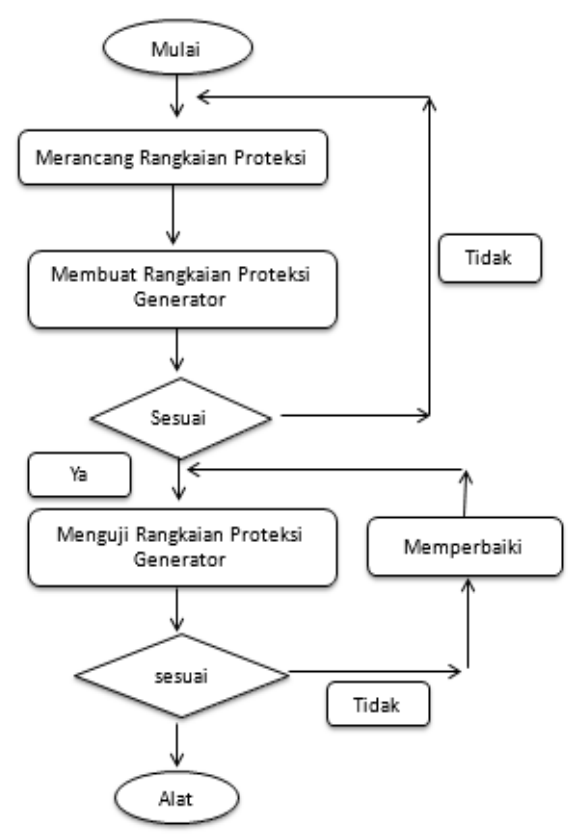

Gambar 3.1 Diagram Alir Pembuatan Alat

\subsection{Perancangan Rele Proteksi Arus}

Gambar 3.2 berikut menunjukan blok diagram proteksi arus motor yang diusulkan. Dalam pembuatan alat proteksi arus motor tiga fasa ini digunakan beberapa komponen dan pemogramannya, yaitu :

- Sensor arus ( ACS712 20A )

- Modul Relay 5V

- LCD dan 12C Converter

- Kontrol dan Indikator

- Modul Arduino UNO

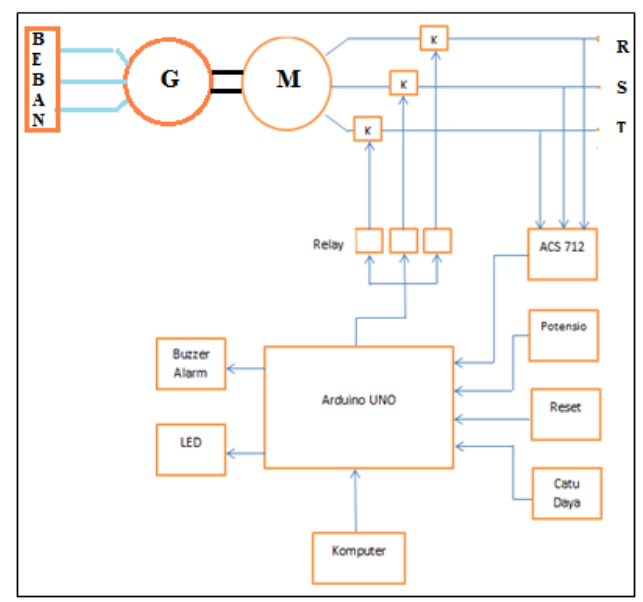

Gambar 3.2 blok diagram proteksi arus motor.

Mikrokontroller arduino UNO digunakan sebagai basis kontrollernya dan alat ukur terhadap arus yang akan diproteksi ini meggunakan ACS712 ELCTR 20A-T, sensor ini dapat digunakan untuk mendeteksi atau membaca arus hingga \pm 20 A untuk AC maupun DC. Cara kerja dari alat proteksi arus motor ini yaitu mendeteksi besarnya arus beban lebih pada generator sinkron tiga fasa dengan beban resistif. Sensor arus ACS712 akan mendeteksi besarnya arus beban lebih yang kemudian akan mengirimkan sinyal ke arduino sebagai input dengan berupa sinyal tegangan yang akan terbaca oleh arduino itu sendiri sebagai inputan analog yang diakibatkan oleh adanya kenaikan arus beban sehingga arduino memerintahkan modul relay untuk men - tripkan kontaktor AC tiga fasa dan memberikan sinyal bahwa terjadi gangguan lewat indikator LED dan buzzer alarm.

\subsection{Pengujian}

Pengujian dilakukan dengan merangkai rangkaian motor dan generator seperti pada Gambar 3.3.

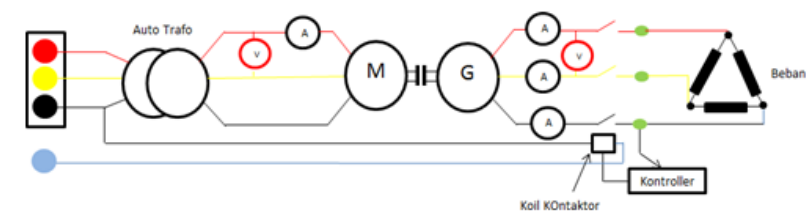

Gambar 3.3 Rangkaian Motor dan Generator

Pengujian dilakukan dengan melakukan simulasi terlebih dahulu dengan menggunakan software, hal ini bertujuan untuk memastikan agar rangkaian dari rele proteksi ini sudah sesuai. Simulasi dilakukan secara langsung dengan menggunakan protoboard (papan simulai elektronik). Pelaksanakan pengujian rele proteksi, dilakukan sesuai dengan rangkaian motor dan generator seperti pada gambar 3.3.

Pengujian rele proteksi bertujuan untuk mendapatkan data yang diinginkan. Pengujian dilakukan dengan beban motor induksi dengan mengukur beberapa parameter seperti arus setting potensiometer, indikator, kondisi relay, dan waktu kerja relay. Metoda pengujian yang akan dilakukan terdiri dari beberapa tahap 
yaitu tahap persiapan, pelaksanaan pengujian, dan perolehan data.

\section{IV . HASIL DAN PEMBAHASAN}

\subsection{Data Percobaan}

Dari hasil pengujian yang telah dilakukan, diperoleh data yang dapat ditampilkan pada Tabel 4.1 dan Tabel 4.2. Pada pengujian rele proteksi arus ini, ada beberapa parameter data yang diperlukan dan melakukan percobaan tersebut dengan menggunakan beban sebanyak enam kombinasi beban dengan acuan pada arus nominal generator yaitu diatur sebesar 7,6 Ampere dan pada beban ke enam yaitu sebesar 8,5 Ampere yang artinya melebihi arus nominal dari generator itu sendiri. Hal ini dilakukan agar dapat mengetahui alat proteksi arus tersebut bekerja dengan baik dan sesuai dengan settingan arus yang akan diproteksi, yaitu dilakukan dengan mengatur potensio pada alat proteksi tersebut.

Tabel 4. 1 Percobaan Dengan Beban Generator

\begin{tabular}{|c|c|c|c|c|c|c|c|c|}
\hline \multicolumn{9}{|c|}{ Sebelum Arus Terukur Melebihi Arus Setting } \\
\hline \multirow{2}{*}{ No } & \multirow{2}{*}{ Beban } & \multirow{2}{*}{$\begin{array}{l}\text { ISetting } \\
\text { (Ampere) }\end{array}$} & Ir & Is & It & \multirow{2}{*}{ Tegangan (Volt) } & \multirow{2}{*}{ Indikator } & \multirow{2}{*}{ KondisiRela } \\
\hline & & & \multicolumn{3}{|c|}{ (Ampere) } & & & \\
\hline 1 & I & 3 & 2,5 & 2,6 & 2,6 & 379,2 & Buzzer off & off \\
\hline 2 & II & 4 & 3 & 3,5 & 3,4 & 379,5 & Buzzer off & off \\
\hline 3 & III & 5 & 4 & 4,2 & 4,5 & 379,4 & Buzzer off & off \\
\hline 4 & IV & 7 & 6,5 & 6,5 & 6,6 & 379,2 & Buzzer off & off \\
\hline 5 & $\mathrm{~V}$ & 8 & 7,6 & 7,6 & 7,8 & 378,3 & Buzzer off & off \\
\hline 6 & $\mathrm{VI}$ & 8,5 & 8,2 & 8 & 8 & 378,6 & Buzzer off & off \\
\hline \multicolumn{9}{|c|}{ Sesudah Arus Terukur Melebihi Arus Setting } \\
\hline \multirow{2}{*}{ No } & \multirow{2}{*}{ Beban } & \multirow{2}{*}{$\begin{array}{l}\text { ISetting } \\
\text { (Ampere) }\end{array}$} & Ir & Is & It & \multirow{2}{*}{ Tegangan (Volt) } & \multirow{2}{*}{ Indikator } & \multirow{2}{*}{ KondisiRele } \\
\hline & & & \multicolumn{3}{|c|}{ (Ampere) } & & & \\
\hline 1 & I & 3 & 3,5 & 4,7 & 4,5 & 379,5 & Buzzer berbunyi & On \\
\hline 2 & II & 4 & 4,5 & 4,6 & 4,6 & 379,4 & Buzzer berbunyi & On \\
\hline 3 & III & 5 & 5,6 & 5,7 & 5,6 & 378,9 & Buzzer berbunyi & On \\
\hline 4 & IV & 7 & 7,3 & 7,5 & 7,3 & 379,7 & Buzzer berbunyi & On \\
\hline 5 & $\mathrm{~V}$ & 8 & 8,3 & 8,5 & 8,5 & 378,8 & Buzzer berbunyi & On \\
\hline 6 & $\mathrm{VI}$ & 8.5 & 8,8 & 9 & 8,7 & 378,4 & Buzzer berbunyi & On \\
\hline
\end{tabular}

Tabel 4. 2 Percobaan Tegangan Tidak Seimbang

\begin{tabular}{|c|c|c|c|c|c|c|c|c|}
\hline \multirow{2}{*}{ No } & \multirow{2}{*}{ Beban } & \multirow{2}{*}{$\begin{array}{c}\text { ISetting } \\
\text { (Ampere) }\end{array}$} & $\mathrm{Ir}$ & Is & It & \multirow{2}{*}{$\begin{array}{c}\text { Tegangan } \\
\text { (Volt) }\end{array}$} & \multirow{2}{*}{ Indikator } & \multirow{2}{*}{ Kondisi Rele } \\
\hline & & & \multicolumn{3}{|c|}{ (Ampere) } & & & \\
\hline 1 & I & 3 & 2,5 & 2,6 & 3,7 & 379,6 & Buzzer berbunyi & $a_{n}$ \\
\hline 2 & II & 4 & 4 & 3,8 & 4,8 & 379,7 & Buzzer berbunyi & $a_{n}$ \\
\hline 3 & III & 5 & 5,6 & 4,7 & 4,7 & 379,4 & Buzzer berbunyi & $a_{n}$ \\
\hline 4 & IV & 7 & 6,5 & 7,6 & 7,7 & 378,6 & Buzzer berbunyi & $a_{n}$ \\
\hline 5 & V & 8 & 15 & 8,3 & 7,3 & 378,3 & Buzzer berbunyi & $\mathrm{O}_{\mathrm{a}}$ \\
\hline 6 & VI & 8,5 & 7,5 & 7,9 & 8,9 & 378,6 & Buzzer berbunyi & $\mathrm{O}_{\mathrm{n}}$ \\
\hline
\end{tabular}

Pada percobaan beban ini diperoleh data seperti yang tertera pada Tabel 4.1 dari beban 1 sampai beban 6 , beban terebut dihubungkan secara star/bintang. Untuk data setting arus dengan potensiometer, serta indikator lainnya dapat dilihat juga, Dimana semua rele bekerja dengan baik sesuai dengan setting arus yang diatur serta waktu dari kerja rele ini konstan yaitu 100 milisecond sesuai dengan jenis proteksi ini yaitu berjenis proteksi rele arus lebih instaneuous. Waktu kerja rele ini bekerja pada saat arus melebihi setting pada rele proteksi sampai terjadinya trip. Nilai waktu kerja dari rele ini di setting dalam program arduino sehingga menjadi konstan. Setiapkali arus motor melebihi arus setting pada rele proteksi, maka rele proteksi akan berfungsi yaitu membuka rangkaian memlaui kontaktor dan indikator buzzer akan berbunyi.

Pada percobaan beban tidak seimbang diperoleh data seperti yang terlihat pada Tabel 4.2 dimana pada percobaan kali ini generator dibebani secara tidak seimbang yang menyebabkan arus pada setiap fasa menjadi tidak seimbang, alat proteksi ini akan tetap membaca ketika salah satu fasa tersebut melebihi setting arus yang telah ditentukan, dengan kata lain maka relay akan tetap bekerja ketika beban tidak seimbang Adapun contoh perhitungan untuk mengetahui tegangan ouput sensor ACS712 serta nilai ADC dengan menggunakan Persamaan 3.1 untuk arus setting 7A pada Tabel 4.2 adalah sebagai berikut:

$$
\begin{aligned}
& \mathrm{V}_{\mathrm{o}}=\frac{1}{2} \mathrm{~V}_{\mathrm{cc}}+\left[\left(\frac{7}{19}\right) * 2.5\right] \\
& \mathrm{V}_{\mathrm{o}}=3.421 \mathrm{~V}
\end{aligned}
$$

Hasil tegangan output sensor ACS712Z adalah $3.421 \mathrm{~V}$

$$
\begin{aligned}
\mathrm{ADC} & =\frac{3,421}{5} \times 835 \\
& =571.30
\end{aligned}
$$

Hasil nilai ADC dengan tegangan output tegangan yang terbaca adalah 571.30.

\subsection{Kurva Karakteristik}

Hasil pengujian yang dilakukan dengan setting arus dan arus beban 
divariaikan diperoleh beberapa kurva karakteristik dari relle proteksi. Gambar 4.1 menunujukan kurva hasil pengujian pada saat setiing arus 3 ampere. Ketika beban generator divariasikan sehingga arus pada motor sekitar 3,5 amper, rele proteksi bekerja dengan waktu tunda $200 \mathrm{~ms}$ sehingga memutuskan suplai tegangan dari saluran sumber ke motor dan alarm berbunyi.

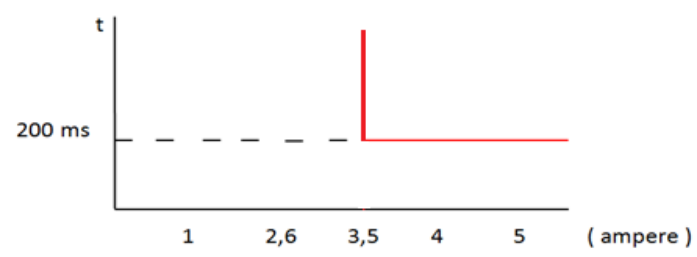

Gambar 4.1 Kurva karakteristik rele dengan arus setting 3 amper

Kurva yang dihasilkan ketika arus setting diatur ke 4 amper ditunjukan pada Gambar 4.2. Rele bekerja pada saat arus mencapai 4,5 amper yang memutuskan kontaktor sehingga motor terputus dari jaringan dengan tunda waktu 200 ms. Kurva karakteristik rele proteksi ini adalah jenis kurva definit, dimana tunda waktunya sama ketika arus motor melebihi nilai arus setingnya. Kurva releyang dihasilkan adalah kurva jenis definit, dimana waktu tundanya sama untuk setiap kelebihan arus pada motor.

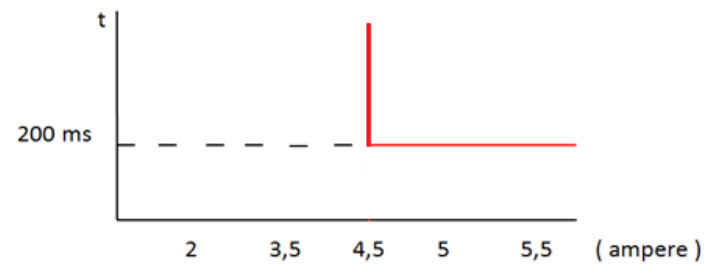

Gambar 4.2 Kurva karakteristik rele proteksi dengan arus setting 4 amper

Gambar 4.3 menunujukan kurva yang dihasilkan pengujian pada saat setiing arus 5 ampere. Ketika beban generator divariasikan sehingga arus pada motor sekitar 5,7 amper, rele proteksi bekerja dengan waktu tunda $200 \mathrm{~ms}$ yang memutuskan suplai tegangan dari saluran sumber ke motor dan lampu tanda menyala.
Terlihat dari kurva bahwa jenis rele ini adalah rele jenis definit.

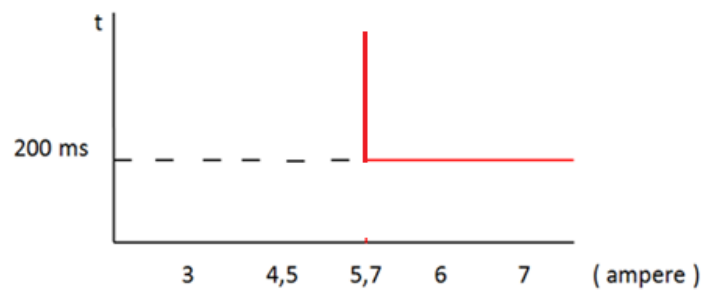

Gambar 4.3 Kurva karakteristik rele proteksi dengan arus setting 5 amper

Kurva yang dihasilkan ketika arus setting diatur ke 7 amper ditunjukan pada Gambar 4.4. Rele bekerja pada saat arus mencapai 7,3 amper dengan tunda waktu 200 ms yang memutuskan kontaktor sehingga motor terputus dari jaringan disertai dengan bunyi tanda peringan alarm.

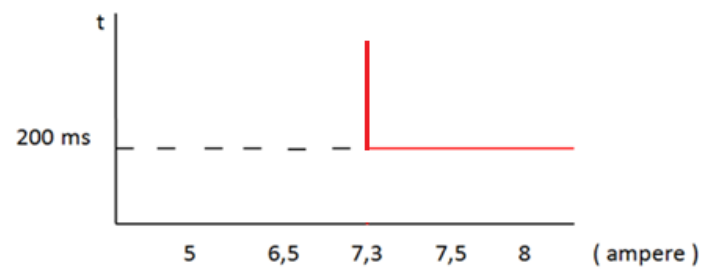

Gambar 4.4 Kurva karakteristik rele proteksi dengan arus setting 7 amper

Gambar 4.5 berikut menunujukan kurva hasil pengujian pada saat setiing arus 8 ampere. Ketika beban generator divariasikan sehingga arus pada motor sekitar 8,5 amper, rele proteksi bekerja dengan waktu tunda $200 \mathrm{~ms}$ sehingga memutuskan suplai tegangan dari saluran sumber ke motor dan alarm berbunyai untuk memperingati operator bahwa ada terjadi gangguan pada motor.

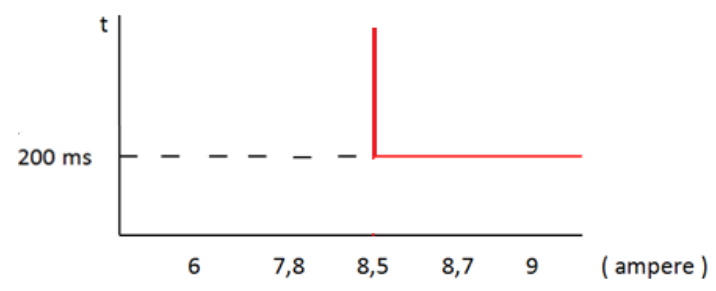

Gambar 4.5 Kurva karakteristik rele proteksi dengan arus setting 8 amper

Kurva karatersitik tersebut menunjukan kinerja dari alat proteksi yang digunakan, ketika arus yang terukur belum melewati arus setting maka proteksi tidak 
akan bekerja, namun setelah arus terukur melewati arus setting maka proteksi tersebut akan bekerja atau berfungsi, serta pada setiap arus setting yang digunakan untuk memproteksi arus lebih pada generator mempunya catatan waktu kerja rele yang sesuai dengan teori yang sudah dijelaskan pada bab 2, dimana jangka waktu kerja rele yaitu mulai saat mengalami pick-up sampai selesainya kerja rele sangat singkat yakni 200 mili detik.

\section{KESIMPULAN}

Berdasarkan hasil pengujian dan analisis data didapatkan beberapa kesimpulan yaitu:

a. Rele proteksi arus lebih motor 3 fasa ini dapat bekerja dengan baik sesuai yang diharapkan

b. Hasil beberapa pengujian rele proteksi ini ketika setting arus sebesar 3, 4, 5, 7, dan 8 ampere dapat bekerja dengan baik dengan waktu tunda pemutusan $200 \mathrm{ms,}$ yang artinya rele proteksi segera bekerja dengan karakteristik waktu seketika.

c. Rele proteksi ini bekerja apabila ketiga fasa melebihi arus yang dikehendaki.

\section{REFERENSI}

1. IEV (International Electrotecthnical Vocabulary) 441-14-20

2. Mashar, Ali.Mesin Listrik II: Politeknik Neegeri Bandung.

3. SNI 04-0225-2000-PUIL-2000, Persyaratan Umum Instalasi Listrik 2000, Badan Standar Nasional, Jakarta, 2000.

4. Rashid, Muhammad. Power Electronics Handbook. San Francisco : Academic Press, 2001.

5. Djuandi, Feri. Pengenalan Arduino, 2011.

6. http://197.14.51.10:81/pmb/ELECT RONIQUE/The\%20Induction\%20

Machine\%20Handbook\%20\%200849300045/0004_PDF_C01.p df;
7. http://www.electricaleasy.com/2014 /02/working-principle-and-typesof.html;

8. http://static.schneiderelectric.us/docs/Circuit\%20Protecti on/0600DB0301.pdf;

9. http://www.electrical4u.com/overcurrent-rele-working-principletypes/;

10. http://www.sayedsaad.com/Protecti on/files/Over_current/1_Overcurren t.htm;

11. Dunn, William C. Fundamental Of Industrial Indtrumentation and Process Control. New York : McGraw-Hill, 2005.

12. Tooley, Mike.Rangkaian Elektronika Edisi Kedua.Jakarta: Erlangga.2003

13. http://www.elekctricaltechnology.or g/2015/01/resistor-typesresistor/fixed-variable-linier-non$\underline{\text { linier.html }}$

14. http://www.allaboutcircuits.com/ele ktkronic-components/16x2-lcdmodule- datasheet;

15. http://www.pcldroid.com/2013/06/r angkaian-star-delta.html

16. http://www.engineergarage.com/ele ctronic-

components/textbook/digital/chpt$5 /$ contactor

17. http://www.learn.sparkfun.com/tuto rials/integrated-circuit/ic-packages 